\title{
Synthesis and Evaluation of Some New Isoquine Analogues for Antimalarial Activity
}

\author{
CHANDRA NATH SAHA, SANJIB BHATTACHARYA* and DIPAK CHETIA
}

Department of Pharmaceutical Sciences, Dibrugarh University, Dibrugarh 786004, Assam, India.

*Bengal School of Technology, Delhi Road, Sugandha, Hooghly 712102, West Bengal, India.

sakkwai@yahoo.com

Received 16 February 2009; Accepted 15 April 2009

\begin{abstract}
Amodiaquine is a 4-aminoquinoline antimalarial that can cause adverse side effects including hepatic and haematological toxicity. The drug toxicity involves the formation of an electrophilic metabolite, amodiaquine quinoneimine (AQQI), which binds to cellular macromolecules leading to hepatotoxicity and agranulocytosis. Interchange of the $3^{\prime}$ hydroxyl and the $4^{\prime}$ Mannich side-chain function of amodiaquine provides an amodiaquine regioisomer (isoquine) that cannot form toxic quinoneimine metabolites. By a simple two-step procedure, four isoquine analogues were synthesized and subsequently evaluated against the chloroquine sensitive RKL-2 strain of Plasmodium falciparum in vitro. All synthesized analogues demonstrated differential level of antimalarial activity against the test strain. However, no compound was found to exhibit better antimalarial property as compared to chloroquine.
\end{abstract}

Keywords: Amodiaquine, Isoquine, Antiplasmodial, RKL-2.

\section{Introduction}

Almost one-half of the world's population is exposed to the threat of malaria and the disease is responsible for two million deaths each year ${ }^{1}$. Chloroquine was a mainstream drug in the fight against Plasmodium falciparum, but its efficacy is being eroded by the emergence of resistant parasites. The spread of chloroquine resistance has prompted the re-investigation of the chemistry and pharmacology of alternative antimalarials such as amodiaquine, an other 4-aminoquinoline which proved to be effective against chloroquine-resistant strains ${ }^{2,3}$.

Amodiaquine is a 4-aminoquinoline antimalarial which is effective against many chloroquine resistant strains of $P$. falciparum ${ }^{4}$. However, clinical use of amodiaquine has been 
severely restricted because of associations with hepatotoxicity and agranulocytosis ${ }^{5,6}$. It has been suggested that the toxicity of amodiaquine is related to the reactive metabolites formed by oxidation of its phenolic side chian, especially to the formation of a quinone imine by cytochrome P-450-catalyzed biological oxidation (Scheme 1) ${ }^{7}$. It has been found that amodiaquine is excreted in bile exclusively as the $5^{\prime}$ thioether conjugates (glutathione and cysteinyl) in rats ${ }^{8}$. This observation indicates that the parent drug undergoes extensive biotransformation in vivo to form amodiaquine quinoneimine (AQQI) or semiquinoneimine (AQSQI) with subsequent conjugation of glutathione?

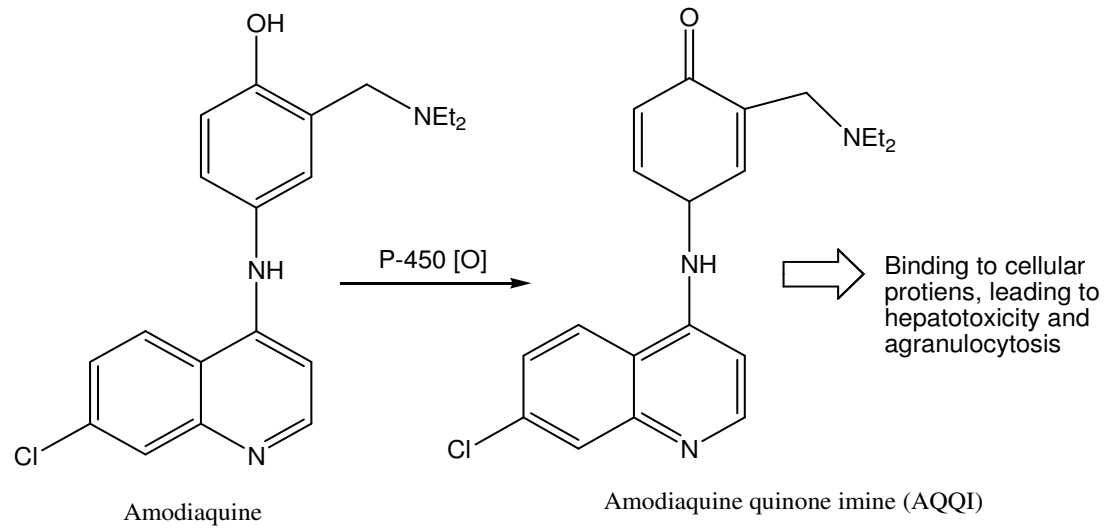

Scheme 1. Bioactivation of amodiaquine to toxic quinoneimine by P-450.

Structure activity relationship (SAR) studies on amodiaquine had previously shown that wide variations in the side chain are accommodated with retention of antimalarial activity. Blocking of bioactivation pathways by removal of the phenolic group or introduction of non reactive substituents has been the main strategy ${ }^{10,11}$. Reducing bioactivation also seems to result in compounds with slower elimination (enhanced biological half life), and increased tissue accumulation ${ }^{12}$.

From SAR studies it has been found that in the amodiaquine and tebuquine series of 4-aminoquinoline analogues, the presence of the 4' hydroxyl group within the aromatic ring imparts greater inherent antimalarial activity against chloroquine resistant parasites than the corresponding deoxo analogues ${ }^{13,14}$. Interchange of the hydroxyl group and the Mannich side chain provides a means of preventing oxidation to toxic metabolites while retaining possible important bonding interactions with the aromatic hydroxyl function. This amodiaquine regioisomer (isoquine) cannot form toxic metabolites by simple oxidation and is potent against chloroquine resistant parasites in vitro (Scheme 2). Isoquine itself has been reported to possess potent in vitro and oral in vivo antimalarial activity in experimental animal models and it does not undergo in vivo biotransformation to quinineimine metabolites ${ }^{15}$. Apart from an excellent antiparasitic profile, isoquine and its different side-chain analogues are rather inexpensive antimalarials to synthesize and may represent new leads for development of a safe, cheap, affordable, and effective antimalarial for both prophylaxis and treatment of malaria. Considering the above said facts we have synthesized a few new isoquine analogues Table 1. The present paper attempts to report the synthesis and in vitro antimalarial properties of those analogues. 


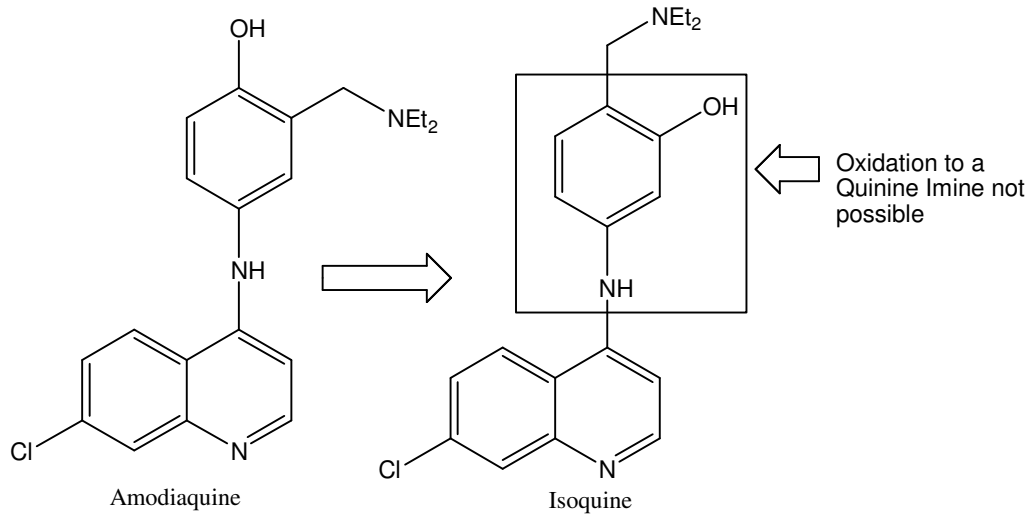

Scheme 2. Redesign of amodiaquine.

Table 1. List of the designed compounds.<smiles>CCCCNCc1ccc(Nc2ccnc3cc(Cl)ccc23)cc1O</smiles>

\begin{tabular}{ccc}
\hline Compounds & $\mathrm{R}_{1}$ & $\mathrm{R}_{2}$ \\
\hline CS-1 & Isopropyl & Isopropyl \\
CS-2 & $\mathrm{H}$ & n-Butyl \\
CS-3 & Phenyl & Phenyl
\end{tabular}

CS-4

$\mathrm{H}$<smiles>Cc1cccc([N+](=O)[O-])c1</smiles>

\section{Chemistry}

The synthesis of isoquine analogues involved a two-step procedure from commercially available starting materials according to a method originally utilized by Burkhalter and coworkers ${ }^{16}$.

Step I: This step involved a Mannich reaction of the commercially available 3-hydroxyacetanilide to provide the Mannich product in yields ranging from 50 to $90 \%$ (Scheme 3).

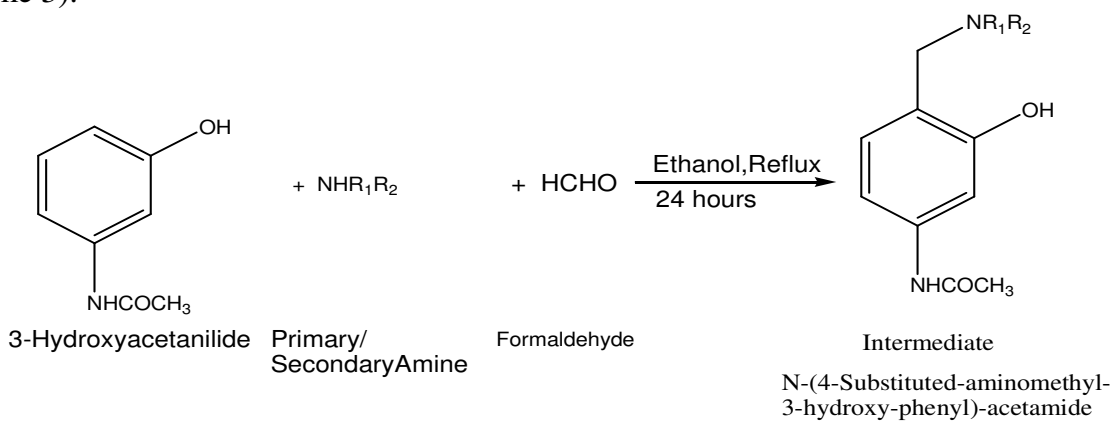

Scheme 3 
Step II: This step involved the hydrolysis of the amide function to provide the corresponding Mannich-substituted 3-aminophenol which was subsequently coupled with 4, 7-dichloroquinoline (Scheme 4) to provide the target molecules shown in Table 1.

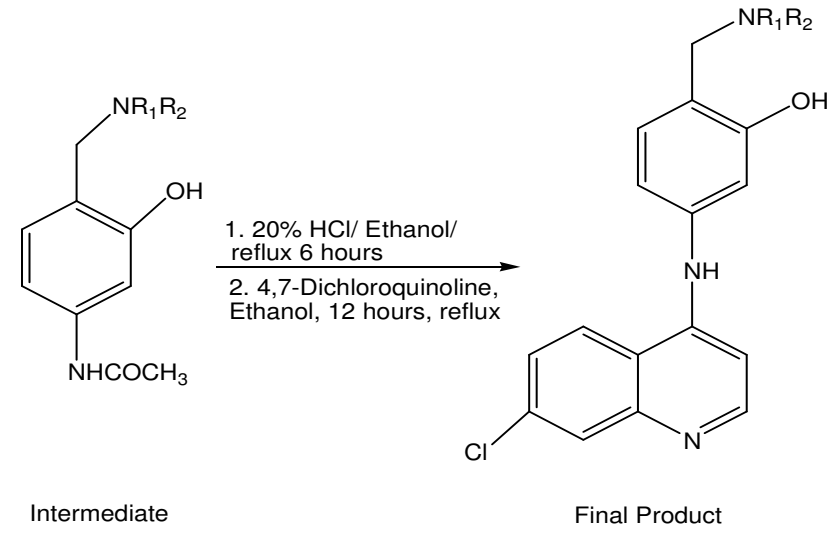

Scheme 4

\section{Experimental}

4,7-Dichloroquinoline was obtained from Mangalam Drug and Organics Ltd., Mumbai as gift sample. All the other chemicals used were of synthetic grade chemicals of Aldrich and Rankem, without further purification and obtained from commercial suppliers.

The completion of reactions was tested by analytical thin layer chromatography on aluminum sheets pre-coated with silica gel obtained from Merck. Visualization was attempted by iodine vapour and UV light. Melting point of the synthesized compounds was determined on Veego, Model No. MPI, by open capillary method. The UV absorption maximum $\left(\lambda_{\max }\right)$ of the synthesized compounds were recorded on Shimadzu UV-1700 UV-Visible spectrophotometer. The FTIR spectra of the synthesized compounds were recorded on Hitachi 270-50 spectrophotometers using potassium bromide pellets. The ${ }^{1} \mathrm{H}-\mathrm{NMR}$ and ${ }^{13} \mathrm{C}-\mathrm{NMR}$ spectra of the synthesized compounds in DMSO were recorded at $400 \mathrm{MHz}$ and $100 \mathrm{MHz}$ respectively by Bruker 400 NMR spectrometer. Chemical shift values are given in $\delta$ (ppm) scale using TMS as an internal standard. Significant ${ }^{1} \mathrm{H}-\mathrm{NMR}$ data are written in order: number of protons, multiplicity (b, broad; s, singlet; d, doublet; t, triplet; $\mathrm{m}$, multiple), coupling constants in hertz, assignment. The mass spectra of the synthesized compounds were recorded on Waters Micromass Q-Tof Micro Mass spectrometer. The $\mathrm{m} / z$ values of the more intense peaks are mentioned.

\section{Synthesis of the targeted compounds}

All the designed compounds (CS-1 to CS-4) were synthesized as per the scheme described in step I \& step II of synthesis by utilizing the following method.

Step I: Ethanol was added to 3-Hydroxyacetanilide in a $100 \mathrm{~mL}$ round-bottom flask followed by one equivalent of primary or secondary amine and aqueous formaldehyde was added and the solution was allowed to heat under reflux for $24 \mathrm{~h}$. After this reflux period, the solvent was removed under reduced pressure and the crude material (intermediate amide) was purified by flash column chromatography using $20-80 \% \mathrm{MeOH} /$ dichloromethane as eluent. 
Step II: Aqueous hydrochloric acid $(20 \%)(25 \mathrm{~mL})$ was added to a round-bottom flask containing the amide (intermediate) and the solution was heated under reflux for 6 hours. The solvent was then removed in vacuo and the resulting residue co-evaporated with ethanol to give the corresponding hydrochloride salt. 4,7-Dichloroquinoline and ethanol $(30 \mathrm{~mL})$ were added, and the reaction mixture was heated under reflux for around 12 hours until completion of the reaction (checked by analytical TLC). A crude product was obtained upon removing the solvent under reduced pressure; this was subsequently purified by flash column chromatography using $20-80 \% \mathrm{MeOH} /$ dichloromethane as eluent to yield the quinoline hydrochloride salt. To liberate the free base compound, this solid was dissolved in distilled water $(18 \mathrm{~mL})$ and the solution was basified by careful drop wise addition of saturated sodium bicarbonate (added until no more precipitate was formed). Dichloromethane $(100 \mathrm{~mL})$ was added, and the free base was extracted into the organic layer. Subsequent drying and removal of solvent in vacuo afforded the desired product.

\section{CS-1: 4-(7-Chloroquinolin-4-ylamino)-2-[(diisopropylamino) methyl] phenol}

CS-1 was obtained as yellowish brown solid (73.95\% yield). $\mathrm{mp}=180-183{ }^{\circ} \mathrm{C}$; UV $\lambda_{\max }$ : $364.0 \mathrm{~nm}$ (DMSO); ${ }^{1} \mathrm{H}$ NMR (400 MHz, DMSO): $\delta 8.37(\mathrm{~d}, 1 \mathrm{H}, J=5.20 \mathrm{~Hz}$, quinoline-H), $\delta 8.07(\mathrm{~d}, 1 \mathrm{H}, J=8.88 \mathrm{~Hz}$, quinoline-H), $\delta 7.89(\mathrm{~d}, 1 \mathrm{H}, J=1.12 \mathrm{~Hz}$, quinoline-H), $\delta 7.34$ (dd, $1 \mathrm{H}, J=1.92,1.92 \mathrm{~Hz}$, quinoline-H), $\delta 7.29(\mathrm{~d}, 1 \mathrm{H}, J=8.16 \mathrm{~Hz}$, quinoline-H), $\delta 6.97(\mathrm{~d}$, $1 \mathrm{H}, J=7.68 \mathrm{~Hz}, \mathrm{Ar}-\mathrm{H}), \delta 6.72(\mathrm{~d}, 1 \mathrm{H}, J=8.40 \mathrm{~Hz}, \mathrm{Ar}-\mathrm{H}), \delta 6.85(\mathrm{~s}, 1 \mathrm{H}, \mathrm{OH}), \delta 6.58(\mathrm{dd}$, $1 \mathrm{H}, J=5.28,5.20 \mathrm{~Hz}, \mathrm{Ar}-\mathrm{H}), \delta 3.76\left(\mathrm{~s}, 2 \mathrm{H}, \mathrm{CH}_{2}\right), \delta 3.10(\mathrm{~m}, 2 \mathrm{H}$, diisopropyl-H), $\delta 1.05(\mathrm{~d}$, $12 \mathrm{H}$, diisopropyl-H); ${ }^{13} \mathrm{C}$ NMR (100 MHz, DMSO): $\delta 157.00,151.84,149.59,149.46$, $135.13,129.86,128.68,125.64,125.25,125.09,123.60,121.41,117.51,117.07,101.30$, 49.56, 48.14, 19.77; IR (in KBr disc): 3425, 3061, 2970, 2897, 2876, 1612, 1568, 1454, 1367, 1261, 1123, 874, $812 \mathrm{~cm}^{-1}$; MS (m/z): $384.0(\mathrm{~m}+)$.

\section{CS-2: 2-Butylaminomethyl-5-(7-chloro-quinolin-4-ylamino) phenol}

CS-2 was obtained as pale brown solid (63.89\% yield). $\mathrm{mp}=101-102{ }^{\circ} \mathrm{C}$; UV $\lambda_{\max }: 367.5$ nm (DMSO); ${ }^{1} \mathrm{H}$ NMR (400 MHz, DMSO): $\delta 8.69(\mathrm{~d}, 1 \mathrm{H}, J=4.80 \mathrm{~Hz}$, quinoline-H), $\delta 8.14$ $(\mathrm{d}, 1 \mathrm{H}, J=8.80 \mathrm{~Hz}$, quinoline-H), $\delta 7.99(\mathrm{~d}, 1 \mathrm{H}, J=3.20 \mathrm{~Hz}$, quinoline-H), $\delta 7.44(\mathrm{dd}, 1 \mathrm{H}$, $J=8.80,6.00 \mathrm{~Hz}$, quinoline-H), $\delta 7.06(\mathrm{~d}, 1 \mathrm{H}, J=7.60 \mathrm{~Hz}$, quinoline- $\mathrm{H}), \delta 6.93(\mathrm{~d}, 1 \mathrm{H}, J=$ $15.20 \mathrm{~Hz}, \mathrm{Ar}-\mathrm{H}), \delta 6.85(\mathrm{~d}, 1 \mathrm{H}, J=8.00 \mathrm{~Hz}, \mathrm{Ar}-\mathrm{H}), \delta 6.75(\mathrm{~s}, 1 \mathrm{H}, \mathrm{OH}), \delta 6.63(\mathrm{dd}, 1 \mathrm{H}, J=$ 5.20, $4.40 \mathrm{~Hz}, \mathrm{Ar}-\mathrm{H}), \delta 3.91$ (m, 2H, $n$-butyl-H), $\delta 3.37$ (s, 2H, $\left.\mathrm{CH}_{2}\right), \delta 2.70$ (m, 2H, n-butyl-H), $\delta 1.56\left(\mathrm{t}, 2 \mathrm{H}, n\right.$-butyl-H), $\delta 1.35$ (t, $3 \mathrm{H}, n$-butyl-H); ${ }^{13} \mathrm{C}$ NMR (100 MHz, DMSO): $\delta 156.48$, $151.24,149.79,149.58,135.18,129.93,128.28,125.61,125.54,125.30,123.49,121.82$, 117.44, 117.24, 101.10, 52.13, 48.38, 31.44, 20.46, 13.70; IR (in KBr disc): 3423,3070 , $1614,1575,1460,1375,1256,1157,1119,874,815,768 \mathrm{~cm}^{-1}$; MS $(\mathrm{m} / \mathrm{z}): 356.0(\mathrm{~m}+)$.

\section{CS-3: 5-(7-Chloroquinolin-4-ylamino)-2-[(diphenylamino) methyl] phenol}

CS-3 was obtained as dark brown solid (74.12\% yield). $\mathrm{mp}=221-224{ }^{\circ} \mathrm{C}$; UV $\lambda_{\max }: 365.5$ nm (DMSO); ${ }^{1} \mathrm{H}$ NMR (400 MHz, DMSO): $\delta 8.70(\mathrm{~d}, 1 \mathrm{H}, J=5.20 \mathrm{~Hz}$, quinoline-H), $\delta 8.11$ $(\mathrm{d}, 1 \mathrm{H}, J=1.6 \mathrm{~Hz}$, quinoline-H), $\delta 8.00(\mathrm{~d}, 1 \mathrm{H}, J=1.6 \mathrm{~Hz}$, quinoline- $\mathrm{H}), \delta 7.58(\mathrm{~d}, 1 \mathrm{H}, J=$ $8.80 \mathrm{~Hz}$, phenyl-H), $\delta 7.44(\mathrm{dd}, 1 \mathrm{H}, J=4.80,2.00 \mathrm{~Hz}$, quinoline-H), $\delta 7.06(\mathrm{~d}, 1 \mathrm{H}, J=8.00$ $\mathrm{Hz}$, quinoline-H), $\delta 7.01(\mathrm{~d}, 1 \mathrm{H}, J=2.80 \mathrm{~Hz}$, phenyl-H), $\delta \quad 6.94(\mathrm{~d}, 1 \mathrm{H}, J=10.00 \mathrm{~Hz}$, phenyl-H), $\delta 6.97$ (d, 1H, J = 2.00 Hz, Ar-H), $\delta 6.90(\mathrm{~d}, 1 \mathrm{H}, J=7.20 \mathrm{~Hz}, \mathrm{Ar}-\mathrm{H}), \delta 6.87$ (s, $1 \mathrm{H}, \mathrm{OH}), \delta 6.68(\mathrm{dd}, 1 \mathrm{H}, J=10.80,5.20 \mathrm{~Hz}, \mathrm{Ar}-\mathrm{H}), \delta 3.85\left(\mathrm{~s}, 2 \mathrm{H}, \mathrm{CH}_{2}\right) ;{ }^{13} \mathrm{C}$ NMR $(100$ MHz, DMSO): $\delta 152.50,151.23,149.66,149.40,142.65,135.65,129.60,129.25,128.61$, 
125.56, 124.97, 124.45, 123.52, 121.42, 120.45, 119.86, 117.81, 117.16, 101.13, 40.45; IR (in $\mathrm{KBr}$ disc): $3405,3060,1608,1560,1440,1375,1310,1260,1119,875,816 \mathrm{~cm}^{-1}$; MS $(\mathrm{m} / \mathrm{z}): 452.1(\mathrm{~m}+)$.

\section{CS-4: 5-(7-Chloroquinolin-4-ylamino)-2-[(3-nitrophenylamino)-methyl] phenol.}

CS-4 was obtained as reddish brown $\left(66.33 \%\right.$ yield). $\mathrm{mp}=240-244{ }^{\circ} \mathrm{C}$; UV $\lambda_{\max }: 367.5 .0$ nm (DMSO); ${ }^{1} \mathrm{H}$ NMR (400 MHz, DMSO): $\delta 8.57$ (d, $1 \mathrm{H}, J=5.30 \mathrm{~Hz}$, quinoline-H), $\delta 8.02$ $(\mathrm{d}, 1 \mathrm{H}, J=2.08 \mathrm{~Hz}$, quinoline-H), $\delta 7.77(\mathrm{~d}, 1 \mathrm{H}, J=8.85 \mathrm{~Hz}$, quinoline-H), $\delta 7.67(\mathrm{~d}, 1 \mathrm{H}, J$ $=2.08 \mathrm{~Hz}$, quinoline-H), $\delta 7.34(\mathrm{~d}, 1 \mathrm{H}, J=8.95,2.13 \mathrm{~Hz}$, quinoline- $\mathrm{H}), \delta 7.23(\mathrm{~s}, 1 \mathrm{H}, J=$ $8.16 \mathrm{~Hz}$, quinoline-H), $\delta 6.83(\mathrm{~d}, 1 \mathrm{H}, J=2.20 \mathrm{~Hz}, \mathrm{Ar}-\mathrm{H}), \delta 6.45(\mathrm{~d}, 1 \mathrm{H}, J=5.35 \mathrm{~Hz}$, quinoline-H), $\delta 6.61(\mathrm{~s}, 1 \mathrm{H}, \mathrm{OH}), \delta 6.01(\mathrm{~d}, 1 \mathrm{H}, \mathrm{Ar}-\mathrm{H}), \delta 3.95(\mathrm{~s}, 2 \mathrm{H}$, amine $) ;{ }^{13} \mathrm{C}$ NMR $(100 \mathrm{MHz}, \mathrm{DMSO}): \delta 154.74,151.79,149.39,148.39,135.72,135.16,130.02,128.59$, $127.73,126.44,121.45,119.93,117.49,100.94,36.74$; IR (in KBr disc): $3205,2880,1600$, 1560, 1454, 1361, 1231, 1096, $815 \mathrm{~cm}^{-1}$. MS (m/z): $420.0(\mathrm{~m}+)$.

\section{In vitro antimalarial screening}

All the synthesized compounds were screened for antimalarial activity in the Regional Medical Research Centre (Indian Council of Medical Research), N.E. Region, Dibrugarh, India.

The in vitro antimalarial assay was carried out in 96 well microtitre plates according to the microassay protocol of Rieckmann and co-workers with minor modifications ${ }^{17,18}$. The cultures of $P$. falciparum RKL-2 strain were maintained in medium RPMI 1640 supplemented with $25 \mathrm{mM}$ HEPES, $1 \% \mathrm{D}$-glucose, $0.23 \%$ sodium bicarbonate and $10 \%$ heat inactivated human serum ${ }^{19}$. The asynchronous parasites of $P$. falciparum were synchronized after $5 \% D$-sorbitol treatment to obtain only the ring stage parasitized cells ${ }^{20}$. For carrying out the assay, an initial ring stage parasitaemia of 0.8 to $1.5 \%$ at $3 \%$ haematocrit in a total volume of $200 \mu \mathrm{L}$ of medium RPMI-1640 was determined by Jaswant Singh Bhattacharya (JSB) staining to assess the percent parasitaemia (rings) and uniformally maintained with $50 \% \mathrm{RBCs}\left(\mathrm{O}^{+}\right)^{21}$. A stock solution of $5 \mathrm{mg} / \mathrm{mL}$ of each of the test samples was prepared in DMSO and subsequent dilutions were prepared with culture medium. The diluted samples in $20 \mu \mathrm{L}$ volume were added to the test wells so as to obtain final concentrations (at five fold dilutions) ranging between $0.4 \mu \mathrm{g} / \mathrm{mL}$ to $100 \mu \mathrm{g} / \mathrm{mL}$ in duplicate well containing parasitized cell preparation. The culture plates were incubated at $37{ }^{\circ} \mathrm{C}$ in a candle jar. After 36 to $40 \mathrm{~h}$ incubation, thin blood smears from each well were prepared and stained with JSB stain. The slides were microscopically observed to record maturation of ring stage parasites into trophozoites and schizonts in presence of different concentrations of the test agents. The test concentration which inhibited the complete maturation into schizonts was recorded as the minimum inhibitory concentrations (MIC). Chloroquine was used as the reference drug.

\section{Observations of the in vitro antimalarial screening}

The mean number of rings, trophozoites and schizonts recorded per 100 parasites from duplicate wells after incubation for 38 hours, and percent maturation inhibition with respect to control group are shown in the Table 2 . The minimum inhibitory concentration (MIC) values in the Table 2 are indicated in italic bold form.

\section{Results and Discussion}

A series of new 7-chloro-4-aminoquinoline Mannich base derivatives were synthesized from commercially available starting materials. In this series the $4^{\prime}$-diethylamino function of isoquine is replaced by a $4^{\prime}$-primary or secondary amino function. The synthesis involved 
the preparation of Mannich base by Mannich reaction of the 3-hydroxyacetanilide followed by hydrolysis of the amide function of the Mannich base. The hydrolysis product (Mannich substituted 3-aminophenol) was subsequently coupled with 4, 7-dichloroquinoline to provide the four compounds. The compounds were characterized by various spectrometric analysis and the results of which are characteristic of the anticipated structure of the synthesized compounds.

Table 2. In vitro antimalarial activity of synthesized compounds against chloroquine sensitive RKL-2 strain of Plasmodium falciperum.

\begin{tabular}{|c|c|c|c|c|c|}
\hline \multirow{2}{*}{$\begin{array}{c}\text { Code No. } \\
\text { (Compound) }\end{array}$} & \multirow{2}{*}{$\begin{array}{c}\text { Concentrations } \\
\text { employed, } \\
\mu \mathrm{g} / \mathrm{mL}\end{array}$} & \multicolumn{3}{|c|}{$\begin{array}{c}\text { Number of parasites/ } \\
100 \text { infected RBCs }\end{array}$} & \multirow{2}{*}{$\begin{array}{c}\text { Percentage } \\
\text { inhibition of } \\
\text { Schizont Maturatior }\end{array}$} \\
\hline & & Rings & Trophozoites & Schizonts & \\
\hline \multirow{7}{*}{$\mathrm{CS}-1$} & 100 & 0 & 0 & 0 & 100 \\
\hline & 50 & 0 & 0 & 0 & 100 \\
\hline & 10 & 0 & 100 & 0 & 100 \\
\hline & 2.0 & 55 & 23 & 16 & 82.22 \\
\hline & 1.0 & 40 & 30 & 26 & 71.11 \\
\hline & 0.5 & 25 & 16 & 59 & 34.44 \\
\hline & 0.25 & 0 & 15 & 85 & 5.55 \\
\hline \multirow{9}{*}{$\mathrm{CS}-2$} & 100 & 100 & 0 & 0 & 100 \\
\hline & 50 & 100 & 0 & 0 & 100 \\
\hline & 10 & 100 & 0 & 0 & 100 \\
\hline & 2.0 & 100 & 0 & 0 & 100 \\
\hline & 1.0 & 100 & 0 & 0 & 100 \\
\hline & 0.5 & 68 & 8 & 24 & 73.33 \\
\hline & 0.25 & 22 & 25 & 53 & 41.11 \\
\hline & 0.125 & 19 & 23 & 69 & 23.33 \\
\hline & 0.063 & 0 & 16 & 85 & 5.55 \\
\hline \multirow{3}{*}{$\mathrm{CS}-3$} & 100 & 0 & 45 & 55 & 38.88 \\
\hline & 50 & 0 & 29 & 79 & 12.22 \\
\hline & 25 & 0 & 22 & 88 & 2.22 \\
\hline \multirow{2}{*}{$\mathrm{CS}-4$} & 100 & 0 & 57 & 74 & 17.77 \\
\hline & 50 & 0 & 36 & 100 & 0 \\
\hline \multirow{4}{*}{ Chloroquine } & 0.50 & 100 & 0 & 0 & 100 \\
\hline & 0.25 & 100 & 0 & 0 & 100 \\
\hline & 0.125 & 95 & 3 & 2 & 97.1 \\
\hline & 0.0625 & 70 & 32 & 8 & 88.4 \\
\hline Control & - & 0 & 10 & 90 & - \\
\hline
\end{tabular}

All the synthesized compounds constitute a series with having modification at the lateral amino group of the side chain (CS-1 to CS-4). The compounds were evaluated for their in vitro antimalarial activity against the chloroquine sensitive RKL 2 strain of $P$. falciparum. The in vitro antimalarial assay was carried out by JSB stained slide method in the Regional Medical Research Centre (Indian Council of Medical Research), N.E. Region, Dibrugarh, India. All the tested compounds showed moderate to average percentage of killing the parasites. Two of the compounds (CS-1 and CS-2) showed comparatively better antimalarial activity under the given test conditions with MIC values of 10 and $1 \mu \mathrm{g} / \mathrm{mL}$ respectively. But none of the compounds demonstrated any appreciable activity better than the reference drug, chloroquine. 
The antimalarial screening result reflects that the compounds (CS-1, CS-2) with alkyl substituted amino group side chain (Diisopropylamine, and $n$-butylamine respectively) showed comparatively higher activity than the compounds (CS-3 and CS-6) with aromatic ring (Diphenylamine and $m$-nitroaniline respectively). Though none of the synthesized compound (CS-1 to CS-4) did not exhibit pronounced level of activity as compared to chloroquine but compounds with aliphatic side chain to the amino side chain showed significant level of activity at a concentration dependent manner. There is another provision to check the significant level of activity against the other strains and species of Plasmodium. The novel 7-chloro-4-aminoquinoline derivatives synthesized and evaluated in the present work may be of help for further modification of the isoquine structure in the antimalarial research for the development of a new generation of 4-aminoquinoline antimalarials in due course.

\section{Acknowledgement}

The authors extend their appreciation to All India Council of Technical Education (AICTE), New Delhi for financial assistance. The authors are also thankful to Dr. Anil Prakash, Dy. Director, Regional Medical Research Centre (Indian Council of Medical Research), N.E. Region, Dibrugarh, Assam, India for antimalarial screening facility.

\section{References}

1. World Health Organization, Malaria Fact sheet No. 94, 2006. Available at: http://www.who.int/mediacentre/factssheets/fs94/en/.

2. World Health Organisation (WHO), Conquering, Suffering and Enriching Humanity: The World Health Report; World Health Organisation Publishers: Geneva, 1997.

3. (a) Watkins W M, Sixsmith D G, Spencer H G, Boriga D A, Karjuki D M, Kipingor T and Koech D K. Lancet I, 1984, 357-359; (b) White N J. Lancet, 1996, 348, 1184 1185; (c) Olliaro P, Nevill C, Lebras J, Ringwald P, Mussano P, Garner P and Brasseur P, Lancet 1996, 348, 1196-1201.

4. Pradines B, Tall A, Prazzy D, Spiegel A, Fusai T, Hienne R, Trape J F and Doury J C, J Antimicrob Chemother., 1998, 42, 333-339.

5. Neftel K A, Woodtly W and Schmid M, Br Med J., 1986, 292, 721- 723.

6. Lind D E, Levi J A and Vincent P C, Br Med J., 1973, 1, 458-460.

7. Naisbitt D J, Williams D P, O'Neill P M, Maggs J L, Willock DJ, Pirmohamed M and Park B K, Chem Res Toxicol., 1998, 11, 1586-1595.

8. Harrison A C, Kitteringham N R, Clarke J B and Park B K, Biochem Pharmacol., 1992, 43, 1421- 1430.

9. Maggs J L, Kitteringham N R and Park B K, Biochem Pharmacol., 1988, 37, 303-311.

10. Ruscoe J E, Tingle M D, O'Neill P M, Ward S A and Park B K, Antimicrob Agents Chemother., 1998, 42, 2410-2416.

11. Naisbitt D J, Ruscoe J E, Williams D, O'Neill PM, Pirmohamed M and Park B K, $J$ Pharmacol Exp Ther., 1997, 280, 884-893.

12. Penali L K, Assi-Coulibaly L, Kaptue B, Konan D and Ehouman A, Bull Soc Pathol Exot., 1994, 87, 244-247.

13. O'Neill P M, Hawley S R, Bray P G, Ward S A and Park B K, Pharmacol Ther., 1998, 77, 29-58.

14. O’Neill P M, Willock D J, Hawley S R, Bray P G, Storr R C, Ward S A and Park B K, J Med Chem., 1997, 40, 437-448. 
15. O’Neill P M, Mukhtar A, Stocks P A, Randle L E, Hindley S, Ward S A Storr R C, Bickley J F, O'Neil I A Maggs J L, Hughes R H, Winstanley P A, Bray P G and Park B K, J Med Chem., 2003, 46, 4933-4945.

16. Burckhalter J H, Tendwick J H, Jones F H, Jones P A, Holcombe W F and Rawlins A L, J Am Chem Soc., 1948, 70, 1363-1373.

17. Rieckmann K H, Campbell G H, Sax L J and Mrema J E, Lancet, 1978, 1, 221-223.

18. Desjardins R E, In vitro techniques for antimalarial development and evaluation; In: Peters W, Richards W H G. Ed.; Handbook of Experimental Pharmacology. Germany: Springer-Verlag; 1984, 179-200.

19. Trager W and Jensen J B, Science, 1976, 193, 673-675.

20. Lambros C and Vanderberg J P, J Parasitol., 1979, 65, 418-420.

21. Singh J, Indian J Malariol., 1956, 10, 117-129. 


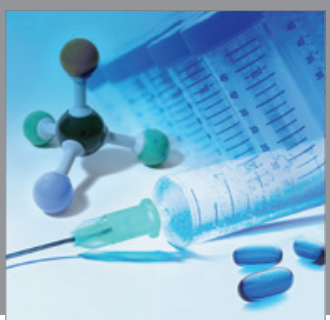

International Journal of

Medicinal Chemistry

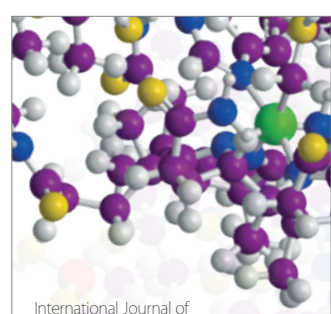

Carbohydrate Chemistry

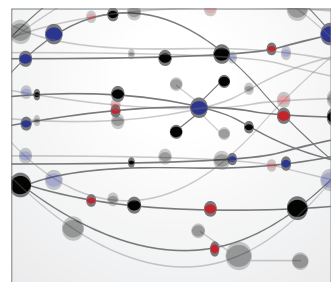

The Scientific World Journal
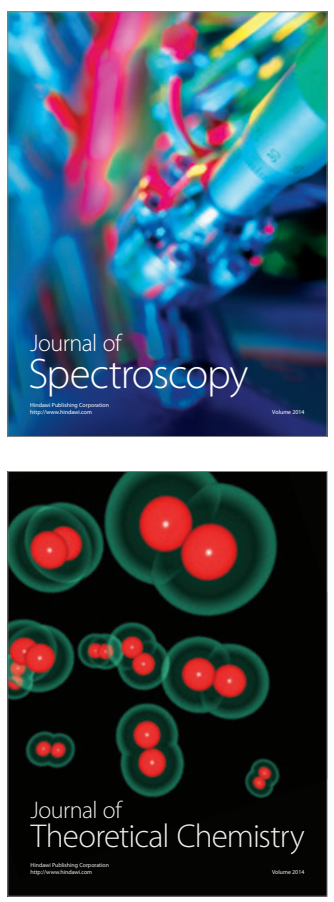
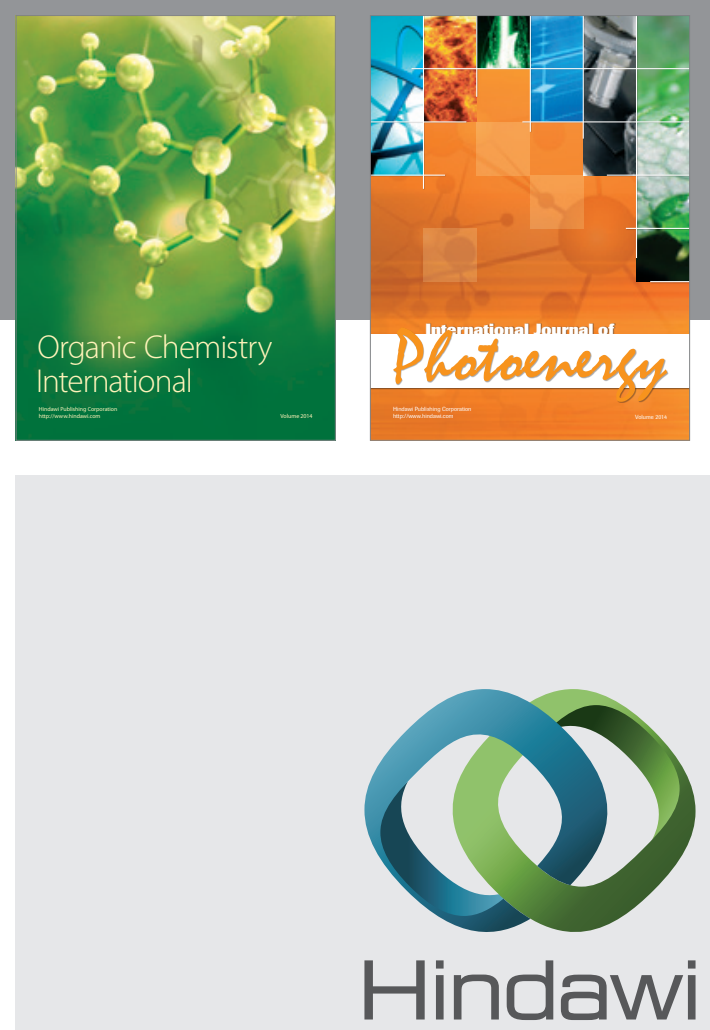

Submit your manuscripts at

http://www.hindawi.com
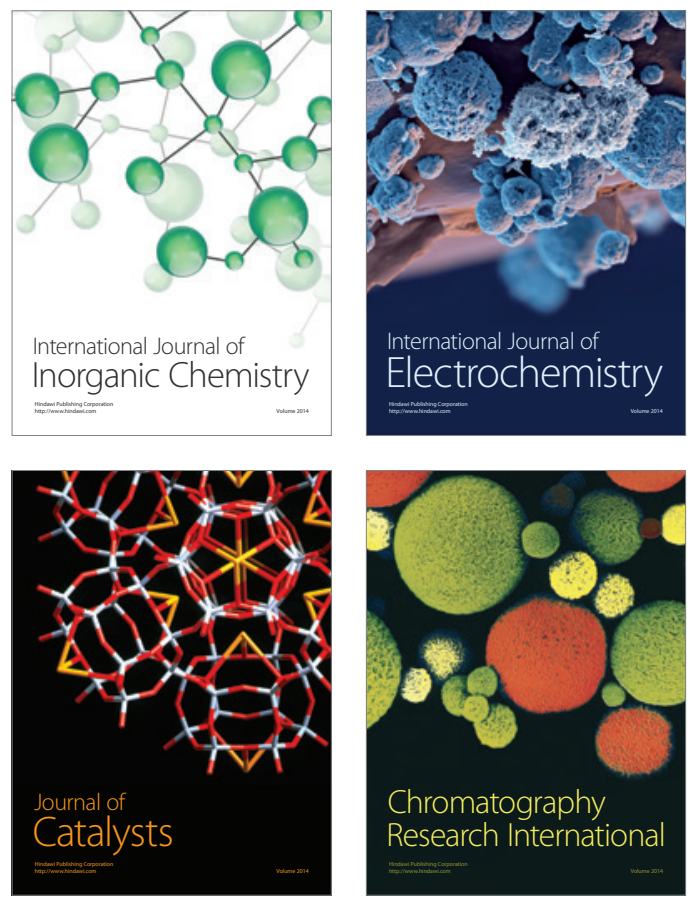
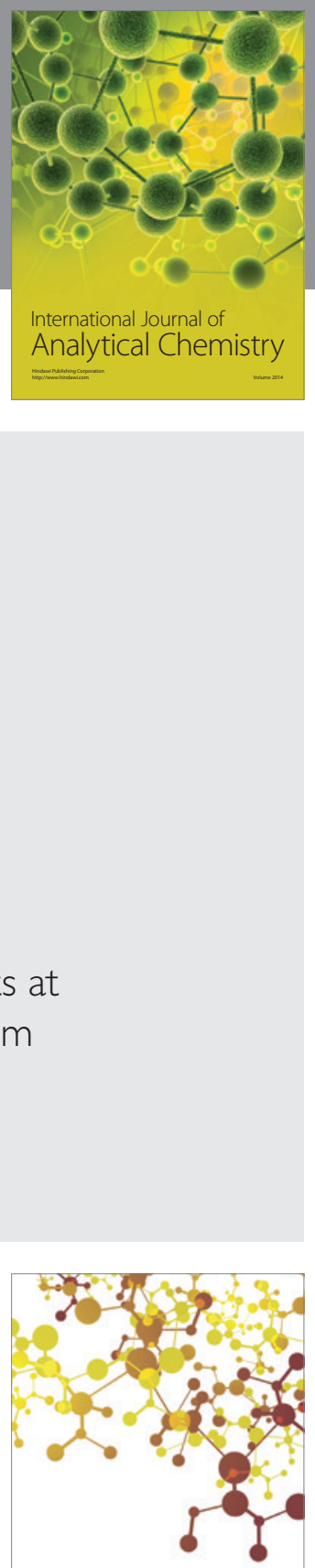

Journal of

Applied Chemistry
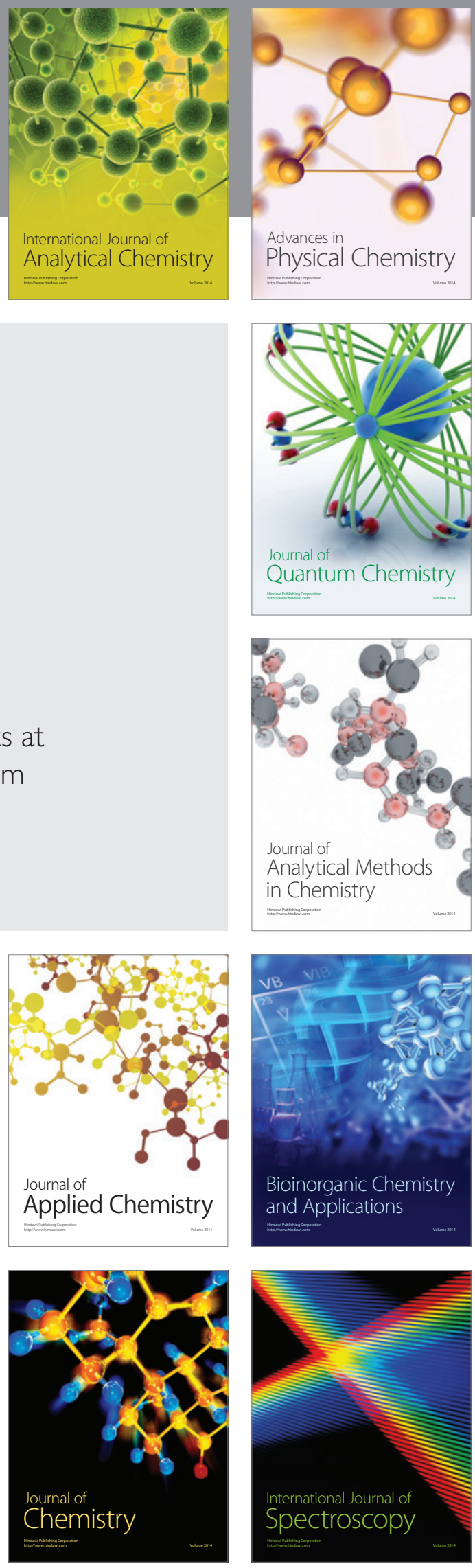